\title{
A Study on Stressors among College Teachers
}

\author{
Dr. Sindhu K. P. \\ Assistant Professor, \\ Post Graduate Department Of Commerce \& Management Studies N. S. S. College, Nemmara, Palakkad \\ District,Kerala - 678508, India
}

\begin{abstract}
The speed at which change is taking place in the worldtoday is certainly overwhelming and breathe taking. In thefast changing world of today, no individual is free fromstress and no profession is stress free. Everyoneexperiences stress, whether it is within the family, business, organization, study, work, or any other social oreconomic activity. Stress has become the core concern in the life of everyone, but still everybody desires stress-free life. Stress is asubject which is hard to avoid.The specific stress experienced by people, often depends on the nature and demands of the setting in which people live. Thus, teachers, engineers, doctors, managersand people in other professions experience different types of stresses to different degrees. The professional role is extremely demanding because they serve to the society. Stress among teachers has become a topic of professional interest but studies relating to teacher'sstress have not been carried out on large scale. Teacher stress can be defined as the experience by ateacher of unpleasant negative emotions such as anger, frustration, anxiety, depression and nervousness, resulting from some aspect of their work (Kyriacou 2001). The study on work stressors among college teachers was conducted on arandom sample of 200 (100 each of male and female) degree college teachers of Kerala State. Questionnaire was used for data collection. Frequency, percentages and chi-square were used for analysis. From the analysis it is clear that majority of the teachers experience stress in their work.
\end{abstract}

Key Words: College Teachers, Stress, Stressors.

\section{Introduction}

Stress is a fact of everyday life. When people reach outfor help, they are often deal with circumstances, situations, and stressors in their lives that leave them feeling emotionally and physically overwhelmed. Modern living has brought with it, not only innumerable means of comfort, but also a plethora of demands that tax human body and mind. Now-a-days everyone talks about stress. It is cutting across all socio economic groups of population and becoming the great leveler. Not only just high pressure executives are its key victims but it also includes labourers, slum dwellers, working women, businessmen, professionals and even children. Stress is an inevitable and unavoidable component of life due to increasing complexities and competitiveness in living standards. The speed at which change is taking place in the world today is certainly overwhelming and breathe taking. In the fast changing world of today, no individual is free from stress and no profession is stress free. Everyone experiences stress, whether it is within the family, business, organization, study, work, or any other social or economic activity. Stress has become the core concern in the life of everyone, but everybody wants stress-free life. Stress is a subject which is hard to avoid. Stress is a part of day-to day living. Every individual is subjected to stress either knowingly or unknowingly. Stressors mainly originate at individual, group,organizational and extra-organizational levels. These relatedirectly to the persons personality and job responsibilities. Thus in modern time, stress in general and job stress in particular has become a part of the life and has received considerable attention in recent years.

The concept of stress was first introduced in the life sciences by Selye Hans in 1936. It was derived from the Latin word 'stringere'; it meant the experience of physical hardship, starvation, torture and pain. Selye Hans, 1936 defined stress as "the non-specific response of the body to any demand placed upon it". Further, stress was defined as "any external event or internal drive which threatens to upset the organismic equilibrium" (Selye Hans, 1956). Another definition given by Stephen Robbins (1999) stress has been stated as "a dynamic condition in which an individual is confronted with an opportunity, constraint or demand related to what he / she desires and for which the outcome is perceived to be both uncertain and important."

Stress affects not only our physical health but our mental well-being, too. To successfully manage stress in everyday lives, individual can learn to relax and enjoy life. Thebest way to manage stress is to prevent it. This may not be always possible. So, the next best things are to reduce stress and make life easier.

Stress refers to any environmental, organizational and individual or internal demands, which require the individual to readjust the usual behaviour pattern. Degree of stress results from events or situations that have potential to cause change. Stimuli or situations that can result in the experience of stress are called stressors. There are three major sources of stress- environmental, individual and organizational. 
Environmental stress is not only caused by the factors intrinsic to job, but by the environmental or extra organizational factors. Stress results because of the individual's interaction with environmental stimuli or factors such as societal or technological changes, political and economic uncertainties, financial condition, community conditions etc.

The stress which an individual experiences in an environment is carried with him in another environment also, thus increasing the stress and causing stress to others also. There are many factors at the level of individual which may be generated in the context of organizational life or his personal life like life and career change, personality types, role characteristics. Any change in career life of an individual puts him in disequilibrium state of affairs and he is required to bring equilibrium. In this process individual experiences stress.

Personality type/characteristic such as authoritarianism, rigidity, masculinity, femininity, extroversion, spontaneity, locus of control are particularly relevant to individual stress. When people become members of several system like family, voluntary organization, work organization etc., they are expected to fulfill certain obligations to each system and to fit into defined places in the system. These various roles may have conflicting demands and people experiences role stress as they are not able to fulfill the conflicting demands or requirements. Stress has been considered as one of the major factors in work organization (Agrawalet al., 1979). Sources of stressors in the employment organization identified by Pestonjee (1992) are work, role, personal development, interpersonal relations and organization climate.

\section{Significance of the study}

The speed at which change is taking place in the world today is certainly overwhelming and breathe taking. In the fast changing world of today, no individual is free from stress and no profession is stress free. Everyone experiences stress, whether it is within the family, business, organization, study, work, or any other social or economic activity. Stress has become the core concern in the life of everyone, but still everybody desires stress-free life. Stress is a subject which is hard to avoid. Work place stress is the harmful physical and emotional response that occurs when there is a poor match between job demands and the capabilities, resources, or needs of the worker. Stress related disorders encompass a broad array of conditions, including psychological disorders and other types of emotional strain, maladaptive behaviors, and cognitive impairment, these conditions may lead to poor work performance or even injury. Job stress is also associated with various biological reactions that may lead ultimately to compromised health, such as cardiovascular disease. Thus in modern time, stress in general and job stress in particular has become a part of the life and has received considerable attention in recent years.

The specific stress experienced by people, often depends on the nature and demands of the setting in which people live. Thus, teachers, engineers, doctors, managers and people in other professions experience different types of stresses to different degrees. The professional role is extremely demanding because they serve to the society. Stress among teachers has become a topic of professional interest but studies relating to teacher's stress have not been carried out on large scale. Teacher stress can be defined as the experience by a teacher of unpleasant negative emotions such as anger, frustration, anxiety, depression and nervousness, resulting from some aspect of their work (Kyriacou 2001).

Stress disturbs the equilibrium of the body. It affects physically, emotionally, and mentally. When individuals experience stress or face demanding situation, they adopt ways of dealing with it, as they cannot remain in a continued state of tension. How the individual deals with stressful situations is known as 'coping'. There are two major targets of coping: changing ourselves or changing our environment. Coping refers to a person's active efforts to resolve stress and create new ways of handling new situations at each life stage (Erikson, 1959)

The goals of coping include the desire to maintain a sense of personal integrity and to achieve greater personal control over the environment. Then he modifies some aspects of the situation or the self in order to achieve a more adequate person-environment fit. Coping thus, is the behaviour that occurs after the person has had a chance to analyze the situation, take a reading of his or her emotions and to move to a closer or more distant position from the challenge.

Since college teachers are engaged in dual roles, i.e., as lecturers, professors and assistant professors, emphasis should be given to management of social and family stressors and job stress so that they can maintain their quality of life and adjust with family members and workmates. The dual responsibilities of home and work, call for multiple roles, which put greater strain on college teachers. Researches comparing the stress level of college teachers are also scanty. Therefore; there is a need to conduct a detailed study on stressorsamong college teachers in this direction. A review of available literature also revealed that no detailed study on this topic has so far been attempted in this direction in Kerala; hence the present study on 'AStudy on Stressors among College Teachers' is undertaken. 


\section{Literature review}

Review of literature in the same area is as follows:

Madhuet al. (1990) conducted a study on role stress: differential influences of someantecedental factors. 173 managerial personnel from steel organization and 76 frompetroleum organization participated in the study. The present study attempted to compare theinfluence of the antecedental factors namely, personal, organizational, job, superior,leadership styles and communication factors on role conflict and role ambiguity. It was foundthat role conflict and role ambiguity experienced by the employees were most significant inthe petroleum organization.

Tharakan (1992) studied on occupational stress and job satisfaction among workingwomen. He observed that professional women experienced greater work related stress thannon-professional women. The expectation of technocrats was much higher than the no technocrats.

Ryhal and Singh (1996) studied the correlates of job stress among university faculty.A sample of 100 faculty members 30 professors, 31 associate and 39 assistant professors.Results revealed that assistant professors experienced higher job stress than associateprofessors and professors.

Orpen (1996) examined the moderating effects of cognitive failure on the relationshipbetween work stress and personal strain. He compared the work stress among 136 nursesand 12 college lecturers. The results found that nurses experienced more stress than thelecturers.

Ansari and Singh (1997) made an attempt to explore the contribution of demographicvariables to the nature of stress experienced by the teachers in an agriculture university. Thestudy comprised sample of 235 faculty members (23 professors, 74 associate and 138assistant professors). The professors were either in moderate or in high stress categories ascompared to associate and assistant professors.

Upadhyay and Singh (1999) compared the occupational stress level experienced bythe 20 college teachers and 20 executives. The teachers showed significant higher levels ofstress than executives on intrinsic impoverishment and status factors. They experiencedstress because their personal wishes and strong desire for better and prosperous career werefelt to be blocked by others.

Aminabhavi and Triveni (2000) revealed that nationalized bank employees havesignificantly higher occupational stress than non-nationalized bank employees, in thedimensions such as role conflict, unreasonable group/political pressure, intrinsicimpoverishment and strenuous working conditions.

Potter et al. (2002) concluded that the interpersonal stressors at work place have theinfluence on the employees. Interpersonal conflicts experienced in the work place also predictdiseases and well-being declines. Results proved that psychosocial environment of workplace have unique effects on employee.

Vashishtha and Mishra (2004) explored the relative contribution of social support andoccupational stress to organizational commitment of supervisors $(n=200)$ the result revealedthat the social support and occupational stress significantly predict the degree oforganizational commitment of supervisors.

Chand and Monga (2007) examined the correlates of job stress and burn out among100 faculty members from two universities. Respondents with internal locus of control, highsocial support and high job involvement experience less stress. Results also revealed that,maximum stress is reported by professors and minimum by assistant professors.

Latha and Panchanatham (2007) found out the job stressors and their implications on the job performance of 40 software professionals. More than $50 \%$ of the respondents do not feel stressed by the working conditions and promotional opportunities. It can be inferred that

IT industry is providing better working environment.

From the above reviews, it is understood that employees are tensioned b stress. In this context, the present study on stressors among college teachers was undertaken.

\section{Objective}

The objective of the present study is to find out the factors influencing stressors among college teachers.

\section{Hypothesis}

H0: There does not exist any significant difference between designation and stressors.

H1: There exists significant difference between designation and stressors.

\section{Research methodology}

The present study is descriptive and explanatory in nature. Both secondary and primary data were collected and used for the study.The secondary data sources for the study include books, journals, periodicals, publication of various organisations and various websites.Primary data required for the study were collected from 200 Arts and Science College teachers of Kerala.Multi-stage sampling was adopted for selection of respondents for the study. In the first stage, the state of Kerala was divided into three regions namely Southern, Central and Northern regions. Southern Region consists of Thiruvanathapuram, Kollam, Pathanamthitta and 
Alappuzha revenue districts of the state. The Central Region includes Kottayam, Idukki, Eranakulam and Thrissur revenue districts of Kerala. Northern Region of the state covers Palakkad, Malappuram, Kozhikode, Wayanad, Kannur and Kasargod revenue districts. In the Second stage by considering the main four universities in Kerala namely, Kerala, Mahatma Gandhi, Calicut and Kannur universities, Thiruvanathapuram district from the Southern Region, Ernakulum district from the Central Region, Kannur and Kozhikode district from the Northern Region were selected for the study. These districts were selected based on judging criteria on the presumption that there are moderately large number of arts and science colleges were situated in these districts and also by giving due consideration to geographical location. In the third stage, 50 college teachers each from these three districts were selected by using convenient sampling method subject to the fulfilment of the inclusion criteria such as gender, income, age, education, designation and size of the family. Thus, the total sample size of the study comes to 200 college teachers from the arts and science colleges. In order to achieve the objectives of the study, a well-structured questionnaire was developed. The questionnaire was finalised after conducting a pilot study among 30 college teachers in Ernakulum district. On the basis of the experience from the pilot study, some of the questions were refined with a view to ensuring the correctness of the responses and included in the final questionnaire. A number of experts/consultants in the human resources area have been consulted and their suggestions were incorporated while finalising the questionnaire to ensure the content validity of the instrument. An assessment of the reliability of the scale of measurement used for measuring the variables is necessary because reliability refers to the degree of dependability, consistency or stability of a scale of measurement. In the present study, the reliability of the scale of measurements used was assessed by using Cronbatch Alpha coefficient, which was above the minimum acceptable level, 0.845 there by confirmed the reliability of the scale of measurement. The questionnaire developed for collecting primary data was administered to 200 college teachers and their responses were collected through filled up questionnaire. The collected data were tabulated and analysed with the help of SPSS. The statistical tools used for analysis include Frequency, Percentage and Chi-square test.

\section{Data analysis and discussion}

Individuals of different designation have different attitudes with regard to stress and coping strategies. Hence it is important to analyse the respondents according to their designation. On the basis of designation, teachers are classified into three category namely associate professors, assistant professors and lecturers. The 200 teachers covered here include 80 (40 per cent) are associate professors, 92 (46 per cent) are assistant professors and 28 (14 per cent) are lectures.

\subsection{Factors causing stress among the degree college teachers}

The circumstances with which the individuals have to work in daily living and the rolesthat they need to play cause stress. The stress caused may motivate or demotivate thesubjects to fulfill their role obligations. Stress causing factors are called as the stressors.According to Pestonjee (1992) the identified sources of stressors in the organization werenamely, work, role, personal development, interpersonal relations and organizational climatestressors, which were further adopted by Telaprolu and George (2005) to develop theEmployment Organization Sources of Stressors scale.For the present study, the respondents were asked to rate the stressors namely work stressors, role stressors, personal development stressors, interpersonal relations and organizational climate in a five point rating scale such as always, frequently, sometimes, rarely and never. Based on the response, mean were calculated and based on the mean ranks were assigned. The result is shown on table Table 1 and Table 2.

Table 1 Organisational Stressors

\begin{tabular}{|c|c|c|c|c|c|c|}
\hline \multirow[t]{2}{*}{ Organisational Stressors } & \multicolumn{5}{|c|}{ Frequency \& Percentage } & \multirow{2}{*}{ Total } \\
\hline & Always & Frequently & Sometimes & Rarely & Never & \\
\hline Work Stressors & $\begin{array}{l}54 \\
(27) \\
\end{array}$ & $\begin{array}{l}69 \\
(34.5)\end{array}$ & $\begin{array}{l}49 \\
(24.5)\end{array}$ & $\begin{array}{l}11 \\
(5.5)\end{array}$ & $\begin{array}{l}17 \\
(8.5)\end{array}$ & $\begin{array}{l}200 \\
(100)\end{array}$ \\
\hline Role Stressors & $\begin{array}{l}24 \\
(12) \\
\end{array}$ & $\begin{array}{l}53 \\
(26.5) \\
\end{array}$ & $\begin{array}{l}35 \\
(17.5)\end{array}$ & $\begin{array}{l}56 \\
(28) \\
\end{array}$ & $\begin{array}{l}32 \\
(16)\end{array}$ & $\begin{array}{l}200 \\
(100)\end{array}$ \\
\hline Personal Development Stressors & $\begin{array}{l}41 \\
(20.5)\end{array}$ & $\begin{array}{l}64 \\
(32) \\
\end{array}$ & $\begin{array}{l}14 \\
(7) \\
\end{array}$ & $\begin{array}{l}43 \\
(21.5)\end{array}$ & $\begin{array}{l}38 \\
(19) \\
\end{array}$ & $\begin{array}{l}200 \\
(100)\end{array}$ \\
\hline Inter PersonalRelationship Stressors & $\begin{array}{l}45 \\
(22.5)\end{array}$ & $\begin{array}{l}24 \\
(12)\end{array}$ & $\begin{array}{l}79 \\
(39.5)\end{array}$ & $\begin{array}{l}37 \\
(18.5)\end{array}$ & $\begin{array}{l}15 \\
(7.5)\end{array}$ & $\begin{array}{l}200 \\
(100)\end{array}$ \\
\hline Organisational Climate Stressors & $\begin{array}{l}27 \\
(13.5) \\
\end{array}$ & $\begin{array}{l}23 \\
(11.5)\end{array}$ & $\begin{array}{l}45 \\
(22.5)\end{array}$ & $\begin{array}{l}86 \\
(43)\end{array}$ & $\begin{array}{l}19 \\
(9.5)\end{array}$ & $\begin{array}{l}200 \\
(100) \\
\end{array}$ \\
\hline
\end{tabular}

Figures in the parenthesis denote percentages. Source: Field Survey

From the Table 1, it is clear that 86 per cent respondents were under the pressure of work stress, 56 per cent respondents were under the pressure of role stress, 59.5 per cent respondents were under the pressure of 
personal development stress, 74 per cent were under the pressure of inter personal relationship stress and 47.5 per cent respondents were under the pressure of organizational climate stress. So it can be concluded that majority of the respondents were under the pressure of work stressors.

The mean and standard deviation is calculated to know the most influencing stress factors. The result is shown in Table 2.

Table 2 Organisational Stressors - Most Influencing stress Factor

Source: Field Survey.

\begin{tabular}{|l|l|l|l|}
\hline Organisational Stressors & Mean & Standard Deviation & Rank \\
\hline Work Stressors & 3.660 & 1.17956 & 1 \\
\hline Role Stressors & 2.905 & 1.29008 & 4 \\
\hline Personal Development Stressors & 3.135 & 1.45166 & 3 \\
\hline Inter PersonalRelationship Stressors & 3.235 & 1.20709 & 2 \\
\hline Organisational Climate Stressors & 2.765 & 1.19032 & 5 \\
\hline
\end{tabular}

From the Table 2 also, it is understood from the mean that the most influencing stress factor is work stressors (mean 3.660) followed by inter relationship stressors (mean 3.235), personal development stressors (mean 3.135), role stressors (mean 2.905) and organizational climate stressors respectively.

In order to test the hypothesis chi-square test was applied. The result of chi square was as follows:

Table3. Chi-Square Results

\begin{tabular}{|l|l|l|}
\hline Stressors & Chi-Square Values & Significance \\
\hline Work Stressors & 27.463 & .001 \\
\hline Role Stressors & 27.206 & .001 \\
\hline Personal Development Stressors & 37.611 & .001 \\
\hline Inter PersonalRelationship Stressors & 25.031 & .001 \\
\hline Organisational Climate Stressors & 46.411 & .000 \\
\hline
\end{tabular}

Source: Field Survey

From the Table 3, it is clear that chi-values are significant at one percent level.

Therefore the alternative hypothesis is proved as:

H1: There exists significant difference between designation and stressors.

\section{Conclusion}

From the forgoing analysis, it is clear that the college teachers are affected by stress especially, work stress. Therefore, it is recommended that they must adapt some coping strategies for overcoming the stress.

\section{References}

[1]. Madhu, K., Ananda, T. V. and Rao, A.N., 1990, Role stress: differential influences of some antecedent factors. Psy. Stu.,35(1):2835 .

[2]. Tharakan, P., 1992, Occupational stress and job satisfaction among working women. J.Indian Aca. App. Psy., 18(1\&2): 37-40.

[3]. Ryhal, P.C. and Singh, K., 1996, A study of correlates of job stress among university faculty.Indian Psy. Rev., 46(1-2): 20-26.

[4]. Orpen, C., 1996, Cognitive failure as a moderator of the effect of work stress on personal strain: An empirical study. Psy. Stu.,41(1\&2): 50-52.

[5]. Ansari, M. R. and Singh, R.P., 1997, A study on nature and extent of stress in teachers and impact of moderators on stress. J. Extn. Edn.,8(2): 1623-1625.

[6]. Upadhyay, B.K. and Singh, B., 1999, Experience of stress: Differences between college teachers and executives. Psy. Stu.,44(3): 65-68.

[7]. Aminabhavi, V.A. and Triveni, S., 2000, Variables causing occupational stress on the nationalized and non- nationalized bank employees. J. Com. Gui. Res., 17(1): 20-29.

[8]. Potter, P.T., Smith, B.W., Strobel, K. R. and Zutra, A. J., 2002, Interpersonal workplace stressors and well-being: A multiwave study of employees with and without Arthritis. J. App. Psy., 87(4): 789-796.

[9]. Vashishtha, A. and Mishra, P.C., 2004, Occupational stress and social support as predictors of organizational commitment. Psy. Stu.,49(2\&3): 202-204.

[10]. Chand, P. and Monga, O.P., 2007, Correlates of job stress and burn out. J.Com. Gui. Res.,24(3): 243-252.

[11]. Latha, G. and Panchanatham, N., 2007, Job Stress Related Problems and Coping Strategies.J.Com. Gui. Res., 24(3):235-242. 